\title{
Innovation Thinking of Contemporary Business Japanese Teaching
}

\author{
Baoling Zhou \\ Hebei University of Technology, Tianjin 300401, China
}

\begin{abstract}
Keywords: Contemporary business Japanese, Teaching innovation, Thinking
\end{abstract}
\begin{abstract}
In order to make our country business Japanese talents to better meet the needs of the current society, it must be sure to set up the courses in business Japanese teaching. However, at this stage in the business of Japanese talent training process and no clear objectives, therefore, it leads to more problems in its teaching process. Articles on contemporary business Japanese teaching innovation question has carried on the comprehensive analysis and research, aiming at problems existing in the teaching process of business Japanese, and put forward the targeted countermeasures of innovation, designed to better improve our country contemporary business Japanese teaching level and quality.
\end{abstract}

\section{Introduction}

At present, accelerating the process of reform and opening up, in the domestic, Japanese firms' investment and the trade is more and more frequent, therefore, to some extent improve the applied Japanese demand for talent, and constantly increase. Based on this situation, the domestic universities and related consulting training institutions began to attention to the cultivation of talents for business Japanese, in the process of teaching courses in business Japanese spoken English courses and negotiation, etc. At present, in colleges and universities and training institutions, the types of courses in Japanese, enrich the increase in the number, but if you want to achieve business Japanese teaching innovation, it is still have greater efforts.

\section{The problem analysis in the teaching of contemporary business Japanese}

\section{Business Japanese course setting is not reasonable}

In order to better meet the needs of contemporary society for business Japanese talents, most of the school courses in the business Japanese, however, in actual teaching process, the concept of business Japanese, and how to cultivate business conforming to the requirements of the society of Japanese talent have comprehensive knowledge and understanding of the problems such as ${ }^{[1]}$.But in this case the courses in the business Japanese is only considering the construction problems of professional course, but not in-depth market research of Japanese enterprises, therefore, in this case is to develop a business Japanese talents training target, and business letter writing courses and trading session goals are not clear.

Because of the unreasonable business Japanese curriculum, make contemporary business Japanese teaching target is not clear, easy to duplicate issues in the educational content, resulting in the teaching of business Japanese integrity and systemic.

\section{The comprehensive quality of business Japanese teachers is not high}

At present stage, the business Japanese teachers have a relatively low level of their own comprehensive quality, and who have rich practical experience of teachers are much rarer. The main reasons for the above phenomenon is the business of Japanese teacher in the learning phase prefer to Japanese language theory knowledge understanding and research, and teachers directly into the business of Japanese teaching jobs after graduation, so, the teachers are lack of communication and trade opportunities for business Japanese.

Most of domestic business Japanese teachers in business etiquette knowledge and trade knowledge are scarce, which enables business Japanese teacher just teach students theoretical knowledge of Japanese language ability, but can't make students to participate in the actual business activities to better implement business Japanese teaching practice, make it difficult to understand in the student 
business Japanese important role and significance in practice, so that the students in the field of international cultural communication ability is very weak ${ }^{[2]}$.

\section{Business Japanese teaching method is backward}

In our business in the process of Japanese teaching, the teacher always uses the traditional teaching method and makes the inadequate communication between teachers and students, it is difficult to arouse the students' learning enthusiasm and initiative, business Japanese, therefore, in the classroom teaching of business Japanese natural cannot give full play to the student's own creativity. Business Japanese teachers in classroom teaching has always been to explain the content of the teaching material as the focus classroom teaching content, so, too much business Japanese teaching of theoretical knowledge, which ignored to develop students' comprehensive quality and the importance of the Japanese language communicative competence.

\section{Innovative business Japanese teaching in terms of BJT examination}

Domestic business Japanese is cramming teaching way, it is usually enclosed or, to some extent affected the students business Japanese speaking ability training, make its daily communication skills in Japanese is very weak. And you want to get right in the BJT exam grades, you must ensure that students learn Japanese environment is good, and the comprehensive quality of teachers themselves should be high, however, these conditions cannot be achieved in Japanese teaching is the current business. In addition, in the business of Japanese teaching, content and methods of teaching materials and the environment and there is a big gap between the localization of Japanese teaching, therefore, BJT examination training requires corresponding reform and innovation.

BJT examination is the business of Japanese ability examination, this form of examination is different from ordinary Japanese level, it mainly displays in: the organizational structure and test structure difference; Specific test is in a different way; Exam content are different priorities. Pay attention to a student in the BJT exam cultural exchange, different scene context communication abilities $^{[3]}$.That is to say, even if the Japanese level exam does not mean that can adapt to the actual environment of Japanese business activities.

Aiming at these problems, the contemporary business teaching innovation must be conducted in Japanese. First, the response to the Japanese syllabus, methods, and teaching material are innovation. China's current business Japanese teaching content and BJT is not consistent with the content of the exam, so to cope with the examination content to conduct a comprehensive in-depth research and discussion, and in view of the actual exam content and its development trend to set up a scientific and reasonable to adapt themselves to the test ideas, and it can really improve students business Japanese teaching content of the examination results. Second, the innovation of contemporary business Japanese teaching method, improve the teachers' comprehensive quality. According to the main content of BJT examination, they can undertake to the student exam training, to give students the opportunity to communicate more Japanese, and to make the students in the process of the actual communication to improve their language communication ability, and can better to improve the teaching level and the comprehensive quality of business Japanese teacher. Arrange for teachers to study abroad or on-the-job training, they can also encourage teachers take an active part in international exchanges, these ways are better able to improve the comprehensive quality of teachers, to make it in business in the course of Japanese teaching to teach students better. Traditional business Japanese teaching, usually the students to listen to, the teacher speak, causes students to open the opportunity to exchange is not much, so, the students in the process of the actual business Japanese is hard to get exercise. So, students should build conducive to its business Japanese to learn the language environment, and actively encourage students in this environment to strengthen the business activities of simulations, and strengthen students' ability of communication in Japanese. 


\section{The innovation case of teaching method business Japanese}

Case teaching method comes from the United States and in the development of our country is not a long time. This teaching method is mainly used in the application of international trade and business management and practice in the process, and the case teaching method is applied to the teaching of business Japanese, you need to carry on the reasonable innovation.

Case teaching is aimed at specific education goal, the teaching process of the real situation of typical processing, and form the specific case of students thinking. By using the method of discussion and research, to improve the students' ability of problem analysis and solving. This kind of teaching method and the traditional way of teaching has certain difference, the purpose of this method is clear, which has a certain practical, comprehensive and dynamic characteristics.

In the business of Japanese application of case teaching in the teaching process can effectively cultivate the students' language ability, to create a more relaxed environment for the students, and teaching material of language knowledge can be applied in the discussion of case study. The students to study in such an environment, not only can strengthen their subject position, at the same time, making it easier to accept class discussion learning method, and in the process of discussion can make students better to strengthen the professional vocabulary and language expression ability to remember. At the same time, this kind of teaching method can in training students' cross-cultural communicative competence to provide a real environment, and make the student to the business culture background and to conduct a comprehensive understanding of the use of the Japanese language environment. Using the live case, students can more in-depth understanding of business Japanese language habits and cultural background, and language application in different backgrounds for the students lay a solid foundation. Case teaching method in training students' business Japanese comprehensive ability also has obvious advantages. Because the case and the answers are used is uncertain, so it can make students stand in a diverse perspective to solve the problem, so you can better improve the students' thinking and the ability to think, to make it faster to master and apply the knowledge for business Japanese to solve the production problems in real life ${ }^{[4]}$.

In view of the case teaching method plays an important part in business Japanese, can undertake innovation from the following aspects, thus better application of the teaching methods.

First, select the case, it should guarantee the truth of case with universality and timeliness, etc., need to have certain representativeness. Business Japanese students compared with the management class and students in language class, its foundation is very weak, so, when choosing the cases difficulty is bigger, but you need to closely with teaching content and purpose. If teachers for the business case are more complex, the students will spend more time to understand, it will weaken students language analysis and expression of teaching purpose. Therefore, in the actual teaching process, teachers need to understand the status of the students to master the extent and the Japanese in time, based on this case and to select the appropriate teaching. In the aspect of practice teaching, the teacher can choose plain mail or business letters as a specific case. Such not only it can make students learn more about business related knowledge, and exercise their ability to analysis, at the same time, it can provide students with examples of language expression, which causes the student to improve the ability of language expression.

Second, in the process of implementing case teaching, it main contains preparation, analysis and summary of the cases. In business Japanese application case is different from management use cases, because of business Japanese case teaching purpose is not to let the students through the case study to understand and master the knowledge of business management, but need in the process of learning to make students better understand and improve its own language expression ability and communication ability, therefore, business Japanese case teaching needs to adjust the teaching based on the actual situation. In preparation for the case, the teacher should be sent to students before the class materials, and let the student through the tool books to learn and study which contains business vocabulary, and through lexical access process, the glossary content expanded and extended, and then expand students' knowledge. Before but that should be paid attention to in case teaching, teachers need to be involved in the education of basic knowledge to explain, so later will be more convenient for students to learn to discuss. Because the student foundation is weak, so if the lack of this kind of teaching 
method as foreshadowing, students accomplishing task analysis has certain difficulty. Therefore, needs to be combined with case teaching methods and teaching so that we can achieve the best teaching effect. And in the process of case analysis discussion, the teacher can through the two points of view to guide and inspire students. One is based on the case analysis and interpretation of the content, the other is by letter or a business culture of case analysis, and interpretation. In the process of case summary, teachers need to analyze and solve problems for students to observe the specific performance, at the same time also can use to finish the homework to the student, and then according to the feedback information carries on the summary and the promotion to help students better. It seems that the business case teaching method innovation of Japanese teaching, teachers must have solid basic skills, and it has comprehensive knowledge of Japanese culture quality and rich practical experience.

\section{The teaching method innovation of static, dynamic video business Japanese}

Static and dynamic video teaching methods mainly include static and dynamic two kinds of video teaching method ${ }^{[5]}$.Among them, the static video teaching mainly include the slides with static images such as photographs. At the beginning of the class teaching, the teacher in order to mobilize students' learning interest, words and phrases can be through the picture; this method can make students grasp the learning content. In addition, the teacher can also be grouped students, and through random q\&a language game teaching objectives and goals. And dynamic video teaching methods mainly include film or a voice, video and other forms of students can listen to the original Japanese original recordings, and to imitate their pronunciation and intonation, if you have problems can ask teachers, thus providing interpretation and help. Students need to practice after recording, and then the video scene simulation and to conduct training session.

Although the static and dynamic video teaching method has certain advantages, but in the actual application process still needs to pay attention to the following:

First, the video watch time should not be too long; it is the best time for five minutes. If viewing time is too long, student experience will disperse and lethargy, and ignore the classroom learning task and purpose, hinder the normal development of classroom teaching.

Second, because of the different student's quality, so video method does not apply to all students, students need to have a certain language can use the teaching method, otherwise the students due to look not to understand boredom and rebellious psychology.

Third, the business of Japanese traditional grammar teaching is not able to be video course more alternative, the main reason is that the video teaching method will disperse knowledge; therefore, in Japanese grammar teaching should be careful when using this teaching method.

\section{Conclusion}

Above all, the contemporary business Japanese teaching is still in the development process, so we need a more in-depth study, thus more effectively improve the level of business Japanese teaching in our country, train more applied business Japanese talent.

\section{References}

[1] Du Junling. Contemporary business Japanese teaching innovation research. Chinese and foreign entrepreneurs,2014(4):232-233.

[2] Xu Jingying. Contemporary business Japanese teaching innovation research. Science and technology entrepreneurs,2013(18):181-181.

[3] Zhang Zhen. The countermeasure analysis of contemporary business Japanese teaching innovation. Journal of wit,2013(5):111-111. 
[4] Yang Yang. Contemporary business Japanese teaching innovation research. Urban tutor (second half),2013(10):18-19.

[5] Peng Yuke. Contemporary business Japanese teaching innovation research. Science times,2015(6):234-234. 